\title{
Roland Barthes e a comunicação: um resgate necessário
}

\author{
Entrevista com Daniel Bougnoux ${ }^{1}$
}

por Flávio Augusto Queiroz e Silva²

1 Filósofo, atualmente professor emérito em Ciências da Comunicação na Universidade Stendhal de Grenoble (França).

2 Graduado em jornalismo pela Universidade de Brasília. Atualmente cursa mestrado na linha de Teorias e Tecnologias da Comunicação, na mesma universidade, onde também integra o Nesecom - UNB (Núcleo de Estudos em Semiótica e Comunicação). flavio.aqs@gmail.com 


\section{Resumo}

Entrevista com o professor francês Daniel Bougnoux, filósofo e atualmente professor emérito em Ciências da Comunicação na Universidade Stendhal de Grenoble (França). A entrevista foi cedida após palestra do professor na Universidade de Brasília, onde falou da importância dos clássicos para o estudo da comunicação. Nesse sentido, recupera o legado teórico do semiólogo Roland Barthes para analisar os fenômenos midiáticos, em uma reflexão que se pretende atual e rigorosa.

\section{Palavras-chave}

Daniel Bougnoux; entrevista; comunicação; teoria; Barthes; semiologia.

\section{Abstract}

Interview with French professor Daniel Bougnoux, philosopher and currently emeritus professor in Communication Sciences at the University Stendhal of Grenoble (France). The interview took place after his lecture in the University of Brasília, where he spoke about the importance of classic works in the study of communication. In this sense, he traces back to the main theories of semiologist Roland Barthes in order to analyze media phenomena, in a reflexion both strict and up-to-date.

\section{Keywords}

Daniel Bougnoux; interview; communication; theory, Barthes, semiology. 
Um dos desafios encontrados por pesquisadores na área de comunicação é o de muitas vezes ter de entender o próprio campo. Assim, como entendêlo? Muitos o classificam como multidisciplinar, transdisciplinar ou até mesmo a-disciplinar. Dado que para muitos os limites e os alcances da área não estão definidos - ou parecem longe de se definir -, algumas discussões provocadas no campo podem parecer efêmeras, dispersas ou carentes de fundamentação teórica de peso.

É justamente posicionando-se contra esse "estado de dispersão" que Daniel Bougnoux veio à UNB (Universidade de Brasília), em novembro de 2011, falar sobre a importância dos clássicos - neste caso, Roland Barthes - para o estudo de questões em voga na Comunicação. O professor francês é autor de inúmeros livros na área, entre os quais La crise de la représentation (La Découverte, 2006), onde aborda a relação entre o avanço das tecnologias de comunicação e a crise nas comunicações institucionais. Além disso, ele participou, em companhia de Régis Debray, da edição do Cahiers de médiologie.

Nesta entrevista, cedida após sua palestra na UNB, retomamos os principais postos expostos pelo professor naquela ocasião. Discutimos algumas questões levantadas por ele em seu último livro e suas opiniões acerca da relação entre a Comunicação e outras áreas do saber.

Flávio A. Queiroz e Silva - É comum dizer com frequência, especialmente no domínio da comunicação ou das ciências da informação, que a tecnologia provoca muitas mudanças e que as transformações são velozes. Neste contexto de euforia com as mudanças, como recuperar os autores e teorias clássicos para continuar pensando o mundo? Por exemplo, no caso de Roland Barthes, ele nos serve ainda para pensar este mundo ou devemos deixá-lo de lado e pensar com autores novos, mais modernos? 
Daniel Bougnoux - Acho importante destacar que não devemos nos fascinar pela tecnologia, que é sempre nova por definição. Eu diria que, quanto aos autores clássicos, eles não envelhecem; isto é, aparentemente os problemas mudam com o avanço tecnológico, mas de fato os problemas de comunicação, ou problemas para a comunidade dos homens advindos do "estar junto", estão muito menos submetidos à mudança do que as tecnologias sempre novas. Por exemplo, as questões levantadas pelo mundo numérico, e que são discutidas acerca do computador, são muito semelhantes às questões discutidas por Platão no século IV a.c., no diálogo Fedro, em torno da invenção da escrita. A escrita que vai matar a memória, que vai tornar os homens ignorantes, que vai torná-los democráticos - que horror! - etc. E poderíamos dizer o mesmo do computador, aliás, nós o dizemos. Há tecnologias sempre novas e problemas sempre antigos, com questões e discussões que andam um pouco em círculos ao longo das gerações, de modo que estamos sempre reencontrando o mesmo tipo de crítica, refutação e objeção. Certos autores colocaram essas questões melhor do que nós poderíamos fazê-lo, e por isso eu insisti em introduzir Platão, Pascal, La Boétie etc nas minhas aulas. Existem reflexões críticas valorosas nos clássicos das quais é melhor não nos privarmos. É necessário termos um pouco de modéstia ao estudá-los, tendo consciência de que talvez eles soubessem tanto ou mais que nós. Assim, nossa disciplina se volta para o passado tanto quanto para a modernidade, e é preciso ganhar essa profundidade histórica ou essa retrospecção. É necessário que a comunicação não seja apenas a conquista do espaço - a internet movimentou o espaço no mundo, nós temos vizinhos dos mais variados lugares, mas quem são nossos vizinhos no tempo? Somos tão vizinhos de Platão, La Boétie, Pascal, Marx, quanto de nossos contemporâneos. Nossos estudos precisam caminhar entre os dois eixos do espaço e do tempo, um não pode atropelar o outro - e, com freqüência em nossos estudos, o fascínio pela redução do espaço nos torna inconscientes da profundidade histórica e nos faz anular a história. Isso é 
um defeito permanente nos estudos em comunicação. É por isso que sou um partidário do retorno aos clássicos para melhor pensar a modernidade.

Flávio A. Queiroz e Silva - Precisamente com relação a Barthes, trata-se de um autor geralmente reduzido, em termos conceituais, ao tema do punctum na fotografia. O que Barthes pode nos trazer ainda de reflexão, para além disso, no domínio da comunicação?

Daniel Bougnoux - Não devemos reduzir um autor clássico - Roland Barthes é um autor clássico - a um slogan. O punctum que você mencionou é importante na sua teorização acerca da fotografia, mas não podemos compreendê-lo senão em referência ao conceito de studium, ou em referência ao conceito de índice conforme Peirce ${ }^{3}$, mesmo se Barthes não menciona essa palavra. Suas ideias giram em torno do fato de que a fotografia é uma impressão. Então, em termos semióticos, para Barthes ela é um índice. E essa questão é muito importante para poder falar da fotografia em comparação com outras imagens que não são indiciais. A foto é indicial, e mesmo as tecnologias do mundo numérico não alteram esse seu aspecto indicial de impressão. Agora, o que Barthes ainda traz aos estudos de comunicação? Acho que ele traz muito porque tem um pensamento exemplar e essencialmente crítico, isto é, ele nos dá os meios para sair da doxa, do senso comum e de uma adesão sempre confortável ao mundo em que vivemos. Barthes é um crítico, e a semiologia, tanto quanto a psicanálise, nos mostra o quanto o mundo não é só isso em que cremos espontaneamente. Por isso Barthes luta contra a espontaneidade e a naturalização e nos mostra as construções em que vivemos, construções sociais, construções técnicas, às vezes construções retóricas. E Barthes, como analista da poética, da retórica, como semiólogo, e eu diria também midiólogo - isto é, atento aos meios, aos meios do teatro da palavra, do teatro do poder, do teatro das instituições - nos torna conscientes daquilo que tendemos 
fortemente a naturalizar. Então este é um aporte, a meu ver, capital. Trata-se de mostrar aos estudantes que o mundo em que vivemos, coletivamente, é artificial, e que portanto poderíamos agir sobre ele e procurar ou sonhar com outras construções. Acredito que Barthes seja um pensador - não um revolucionário, porque ele detestava essa ideia de revolução muito ingênua, sentimental -, alguém que nos torna conscientes das construções sociais e midiáticas do nosso mundo. E a semiologia é uma ferramenta crítica da qual Barthes se vale. Ele olha para objetos culturais bem visíveis dos anos 1950 e tenta decifrá-los, e é esse exercício de deciframento que poderíamos fazer ainda hoje. Isso seria, sem dúvida, necessário para nos tornarmos menos ingênuos e menos dóceis em relação ao mundo do espetáculo, do marketing etc. Então, como se vê, não é Barthes que está ultrapassado, mas talvez nós que não temos a energia e o talento necessário para escrever outras Mitologias ${ }^{4}$

Flávio A. Queiroz e Silva - No Brasil, determinados autores constatam um estado atual de dispersão conceitual no domínio da comunicação, muitas vezes devido a um movimento interdisciplinar no uso de conceitos e ideias que não é proveitoso para o campo, justamente por ser dispersivo. Qual sua opinião a respeito? Existe na França este mesmo estado de dispersão?

Daniel Bougnoux - Sim, eu diria que este é o pecado original, a doença infantil, dos estudos em comunicação. Ao mesmo tempo nós dizemos com orgulho: "somos uma interdisciplina", e isso parece um valor, enquanto é também um terrível obstáculo. Eu diria que os jovens que entram nos cursos de comunicação na França vêm de todos os horizontes disciplinares. Numa faculdade de comunicação nós temos pessoas da História, Economia, Literatura, Filosofia - eu venho da Filosofia, por exemplo -, e temos também engenheiros de som, capturadores de imagem, técnicos de câmera. Tudo isso é totalmente estarrecedor. Um congresso de Ciências da Comunicação é uma torre de Babel,

$4 \quad$ O professor refere-se ao livro Mitologias, de Roland Barthes, que analisa e discute a cultura de massa e do consumo de produtos e propagandas. 
ninguém fala a mesma língua, paradoxalmente, já que estamos no âmbito da Comunicação. Trata-se assim de uma situação que de fato não é frutífera e que deve ser vencida por uma cultura comum. Como gerar uma cultura comum a partir desse conjunto de saberes, curiosidades, linguagens (porque cada um tem sua linguagem, sua história, seu mundo próprio)? Era assim que eu tentava trabalhar, fornecendo fundamentos conceituais, ou reagrupando os pensamentos, não numa grande doxa ou numa grande teoria suprema, mas procurando fornecer passarelas, pivôs, conceitos-chave para que houvesse um mínimo de linguagem comum. A Linguística trouxe diversos conceitos, ela foi de certa forma inspiradora e piloto de modo geral, e os pesquisadores bem posicionados na área de Comunicação são aqueles que passaram pela semiologia ou semiótica, pelas ciências da linguagem, pela análise do sentido. Há também a Psicanálise, que eu diria ser certamente periférica, mas que não deixa de acrescentar e ser importante para a inteligência do campo da Comunicação. É importante trabalhar com essa traducibilidade, a palavra tradução se torna palavra-mestra nos estudos em geral. Comunicar é traduzir, traduzir do mundo de um para o mundo de outro e torná-los mais amplos. A tradução é um exercício importante e é necessário atiçar o gosto por ela, mostrar aos estudantes que sua disciplina não é o todo do fenômeno. Ela é um corte parcial do mosaico e deve-se percorrê-lo. Nenhum problema de comunicação é tratável por uma só disciplina, por isso é necessário abrir-se ao diálogo e à tradução. Há muito trabalho que a disciplina deve fazer sobre si mesma para conquistar uma certa audiência, para que as pessoas a escutem simplesmente como disciplina e não como uma torre de Babel.

Flávio A. Queiroz e Silva - Em seu último livro, A crise da representação ${ }^{5}$, você trata a crise da representação política pelo viés de uma crise da representação em termos gerais. Qual é a relação entre as duas? 
Daniel Bougnoux - Eu parto da ideia de representação como oposta à de presença. Na arte do século $\mathrm{XX}$, assim como na ideia que nós temos da representação política, há uma substituição, uma delegação, um corte semiológico. Na construção de um artefato, por exemplo, o quadro não é a coisa mesma, o quadro é uma imagem artificial. Distante do mundo, o quadro soma-se ao mundo. Do mesmo modo, o deputado soma-se ao mundo dos cidadãos como representante, isto é, ele é delegado. Há uma ruptura entre o representante e o representado. Isso é um efeito bem geral e antigo do que eu chamo de grafosfera, isto é, uma maneira de comunicar pela linguagem, pela escrita, que afasta o mapa e o território, o representante e o representado, o símbolo e a coisa mesma. O real trabalhou para desenvolver e destruir a hierarquia. $\mathrm{Na}$ arte, por exemplo, com o ready-made, com o expressionismo, com o teatro da crueldade, com manifestações muito físicas, corporais e cruas, o fenômeno ganhou destaque no campo artístico, ou no espaço do museu, do palco. Então existe uma fundição simbólica entre o representante e o representado. A crise da representação é entendida no sentido de que ser moderno é ser direto, pulsional, é procurar a imediatez, e não os rodeios pelas mediações instituídas, políticas, da linguagem, culturais. Isso me chamou muito a atenção no domínio da arte e também no domínio da política, afinal a arquitetura democrática de representante-representado está em crise por conta das manifestações populares, de rua, onde as próprias pessoas se apresentam e protestam no intuito de serem ouvidas diretamente. Com as novas mídias existe, então, este desejo de pôr em crise as mediações e representações antigas: a modernidade no geral é uma aceleração de circuitos de comunicação, que, para melhor crescer, atropelam as mediações antigas. Na época em que escrevi o livro estava muito sensível aos aspectos negativos desse processo, mas hoje vejo com bons olhos. Por exemplo, a internet traz um novo elemento, com a internet o receptor é também emissor, um leitor de jornal é também um documentarista, cada um pode ser fotógrafo, músico, cineasta. Há uma participação que reduz a distância entre criador e criatura, uma criatividade que circula melhor e que horizontaliza 
emissor e receptor, e isso coloca uma dúvida: como ficam as antigas mediações? Creio que seja uma medida democrática bem-vinda, já que há menos separação de papéis, de poder, de desigualdades entre as tarefas. Na política, isso reflete em uma democracia mais participativa, porque a ideia de representação traz um pouco de passividade. Nessa crise da representação podemos então dizer que a representação não nos basta, ela não é totalmente democrática, ela torna as pessoas passivas diante do espetáculo.

Flávio A. Queiroz e Silva - Em que patamar você colocaria esse estudo sobre a crise da representação? Trata-se de uma análise propriamente comunicacional ou você o considera uma reflexão a partir de outros olhares?

Daniel Bougnoux - Veja, eu não sei o que seria uma análise propriamente comunicacional. Eu venho da Filosofia, passei pela Literatura, o conceito de representação é muito forte nessas áreas e na Arte também, e, penso eu, central para todos os fenômenos de comunicação. Então eu não tenho os escrúpulos de propor esse livro como um estudo dentro das Ciências da Comunicação. A bem da verdade eu não sei o que é puramente da Comunicação, acho que não há nada de puro - ela é a análise da maneira pela qual nós tornamos possível a existência da comunidade, pelas nossas trocas, de como construímos esse mundo comum. A representação me parecia de fato uma maneira de organizar, de modo central, na era clássica, o que era comum na comunidade. Depois no século XX, tanto pela arte quanto pela política, acontece uma forma mais direta de estar junto, de trocar, de construir o mundo comum. Então era isso que eu queria esclarecer, ao menos pra mim mesmo, por uma análise das mídias, porque a imprensa está evidentemente em plena transformação. E a questão do gravado em relação ao ao vivo é crucial, porque em geral a informação circula gravada, mas hoje, e cada vez mais, a informação procura a transmissão direta. O ao vivo desestrutura a hierarquia da representação e funciona sob a égide do índice, da impressão, do regime de partilha imediato. Nesse sentido, a crise 
da representação se dá também porque a representação tem uma carga muito mais intelectual, trata-se de uma informação filtrada por diferentes mediadores, enquanto que na procura do direto há uma tomada contagiante, uma tomada em massa do mundo, e não permanecemos mais no mesmo esquema vertical, hierárquico. Pelas mídias, pelas obras de arte e pela representação política, creio ter me inclinado em direção ao fenômeno central que é a passagem ao direto, a imediatez contra a mediação. Eu mudei meu ângulo de visão e hoje vejo muitas contribuições positivas deste processo, desta transformação. Acho que essa noção de presença versus representação, ao vivo versus gravado, contato ou índice versus ordem simbólica, me parece central para a compreensão das mudanças no mundo contemporâneo.

Flávio A. Queiroz e Silva - Gostaria de retornarao ponto da interdisciplinaridade. Você mencionou não acreditar numa Comunicação totalmente pura. Nesse caso seria impossível edificar um saber completamente autônomo?

Daniel Bougnoux - Seria, porque ninguém sozinho de fato é capaz de cobrir o domínio dos fenômenos comunicacionais, que são muito numerosos e diversos. Trata-se realmente de um mosaico, sem hierarquia excessiva. Mesmo que haja disciplinas mais bem posicionadas que outras, por exemplo, penso que a Linguística e a Semiologia são disciplinas-piloto dentro desse mosaico. Mas, ainda como exemplo, dentro do que chamamos de estruturalismo, e em Lévi-Strauss particularmente - que antecipou muita coisa sobre a comunicação e escreveu intensamente sobre isso - havia a ambição de aplicar a lingüística de Saussure e Jakobson ao domínio dos intercâmbios não apenas lingüísticos como também matrimoniais e econômicos. Então, essa pesquisa - que creio ser algo abusiva - de uma estrutura reguladora das trocas humanas, em termos demasiado formalistas, é de fato um sonho de comunicação. Ele esperava alcançar uma espécie de cristal a partir do qual a sociedade se dá em transparência nesses diferentes intercâmbios, sejam lingüísticos, matrimoniais, de parentesco, de 
comunicação, ou ainda de bens e serviços. Acho que a ambição lévi-straussiana é exorbitante, utópica e prematura, ou se trata apenas, talvez, de uma doença infantil. Isto é, um sonho de uma ordem absolutamente perfeita de uma disciplina, em torno de um grande modelo como Saussure ou Jakobson. E esta foi uma grande onda nos anos 1950, mas não foi nem generalizável nem durável, faz parte agora da história de uma disciplina. Depois disso surgiram outras ondas, como a arrebentação do mar que vai e vem e recomeça. É o que nós fazemos, surfamos sobre essas ondas, como um esporte. Eu diria que a pesquisa em comunicação é, precisamente nesse sentido, um jogo, um esporte, ou seja, é necessário ser um pouco artista para pensar esses fenômenos e tratar deles. A comunicação é ela mesma uma arte, cada um comunica a seu modo, organiza seu mundo próprio, em compromisso ou ressonância com o mundo dos outros. Não há regras transcendentais ou autoritárias para fazer isso, é uma bricolagem mesmo, trata-se de modos de fazer. Assim a "ciência" faz com que o encontro desses modos de fazer seja ele mesmo uma arte, eu diria, ou um jogo.

Flávio A. Queiroz e Silva - Mas ao mesmo tempo devemos tomar cuidado para não nos perdermos na dispersão conceitual de que falávamos anteriormente...

Daniel Bougnoux - (risos) Exatamente, é necessário ter cautela para não se deixar ditar pelos interesses, gostos e objetivos dos outros. Deve-se começar por sua própria situação no mundo, porque a comunicação é um problema totalmente íntimo e pessoal para cada um. Não podemos, formalizando ou teorizando esses fenômenos, romper conosco mesmos, nem, ao estudarmos, romper com nosso mundo e nossa curiosidade. Já há bastante, no nosso próprio mundo, para pensar a comunicação - porque ela é completa em cada um. Ela é psicológica, semiológica, econômica, histórica. Há muito de nós mesmos na maneira como estudamos a comunicação e não devemos nos privar disso. Eu penso, por exemplo, na psicanálise - para mim ela é incontornável -, eu a 
atravessei em meu percurso de estudos e para mim é uma disciplina importante, mas para outros não o é. Acho que cabe a cada um exprimir suas prioridades e curiosidades por meio dos estudos.

Flávio A. Queiroz e Silva - Há, na França, alguma discussão sobre a Comunicação como ciência autônoma?

Daniel Bougnoux - Sim, claro, cada disciplina sonha com a autonomia, em fundar-se na pureza. Esse sonho da Comunicação surgiu nos anos 1970 na forma de um grande desejo de se fazer reconhecer, e portanto de parecer pura. Havia sim essa grande fantasia de autonomia. Por exemplo, em Grenoble, onde eu dava aulas, houve a criação do prédio principal do departamento de Comunicação, um ato de fundação muito importante, porque antes disso a Comunicação localizava-se no prédio da Faculdade de Letras e nós parecíamos dependentes da Literatura, meio que subalternos ou impuros. Então querendo afirmar nossa autonomia e especificidade foi importante essa mudança de prédio. Mas também, de certa forma, com essa mudança, que aconteceu bem rápido, nós nos separamos por assim dizer do tecido vivo do resto do campus. E acho que essa ruptura, na ânsia pela autonomia, foi justamente também uma perda em comunicação, isto é, em intercâmbio com nossos colegas da Filosofia, da Literatura, das ciências da linguagem etc. Então ficamos lá Ionge, isolados, no novo prédio, e o que achamos ter ganho foi provavelmente uma perda. Há então um paradoxo, pensar a Comunicação como independente, mas também deixá-la bem aberta, ligada e em diálogo com as Ciências Sociais em geral sob pena de que ela se esclerose em seu sonho de independência. Acho que a Comunicação, mais do que outras disciplinas, precisa da fertilização por meio desses diálogos. Na própria dinâmica do ensino, pelo menos na França, os alunos começam o curso de Comunicação depois de passar por aulas e cursos das Ciências Sociais. Isso é algo bom, porque começar muito cedo uma especialidade é uma ilusão, 
uma carga muito pesada para a Comunicação. Assim, o problema institucional, a grade curricular, o lugar do departamento no campus, o lugar desses estudos no espectro do saber, tudo isso coloca uma questão muito precisa sobre o estatuto dessa disciplina. De todo modo, nada disso está muito regrado, e acho que ainda vamos passar muitos anos nesse debate. 


\section{Referências}

BARTHES, R. Mitologias. Rio de Janeiro: Difel, 2003.

MARTINO, L. Uma Questão Prévia: existem teorias da comunicação? In: Martino, Luiz C. (Org.) Teorias da Comunicação: Muitas ou Poucas? São Paulo: Ateliê Editorial, 2007.

NETO, A. F. Dos sintomas aos programas de estudo. Revista Brasileira de Ciências da Comunicação. São Paulo, v. XVIII, n. 1, p.11-25, jan/jun. 2005. 